\title{
Determinação Simultânea de Ocratoxina A e Alfa em Farinhas de Trigo
}

Larine Kupski (I), Mariane de Paula (I), Priscila Scaglioni (I), Juliana Guerra Vieira (I), Maria Isabel Queiroz (I), Eliana Badiale Furlong (I)

(I) FURG - Universidade Federal do Rio Grande (Avenida Itália km 8 - Programa de PósGraduação em Eng e Ciência de Alimentos)

\section{Resumo}

Entre as micotoxinas conhecidas por contaminarem alimentos, destaca-se a ocratoxina A (OTA), pela sua característica carcinogênica, nefrotóxica e teratogênica. Métodos biológicos têm sido investigados para diminuição do seu teor em alimentos tendo como principal via de degradação a hidrólise da ligação amida que liga a porção isocumarina não tóxica da OTA (OT $\alpha)$ com a molécula de fenilalanina. Por essa razão, o desenvolvimento de métodos analíticos que permitem uma confiável identificação, quantificação e detecção a baixos níveis de concentração para ambos os compostos são necessários. Neste trabalho foram estudadas a extração e detecção simultânea de OTA e seu metabólito OT $\alpha$ de farinhas de trigo. O padrão de OT $\alpha$ foi preparado por hidrólise ácida de padrão de OTA. A extração foi realizada através da hidrólise com $\mathrm{HCl} 2 \mathrm{~N}$ e partição com clorofórmio. A agitação do sistema foi realizada em vortex durante 1 minuto, com posterior remoção da fração clorofórmica. A separação e determinação de OTA e OT $\alpha$ foram realizadas em CLAE-FL. A corrida cromatográfica foi realizada à $35^{\circ} \mathrm{C}$, com vazão de $0,6 \mathrm{~mL} \cdot \mathrm{min}^{-1} \mathrm{com}$ detector de fluorescência (FL) nos comprimentos de onda de excitação e de emissão $333 \mathrm{~nm}$ e $460 \mathrm{~nm}$, respectivamente. Os extratos secos foram ressuspensos em $1 \mathrm{~mL}$ da mistura de solventes que compõe a fase móvel (50\% de Acetonitrila e 50\% de água Milli Q acidificada 1\% com ácido acético) e injetados em CLAE (coluna Kromasil C18 $5 \mu \mathrm{m} 250$ x 4,6 mm), com injetor com alça de $20 \mu \mathrm{L}$. A eficiência da separação cromatográfica

\footnotetext{
Referência:

Larine Kupski, Mariane de Paula, Priscila Scaglioni, Juliana Guerra Vieira, Maria Isabel Queiroz, Eliana Badiale Furlong. Determinação Simultânea de Ocratoxina A e Alfa em Farinhas de Trigo. In: Anais do 12을 Congresso Latinoamericano de Microbiologia e Higiene de Alimentos - MICROAL 2014 [= Blucher Food Science Proceedings, num.1, vol.1]. São Paulo: Editora Blucher, 2014. 
foi pelo fator de retenção $(\mathrm{k})$ e fator de separação $(\alpha)$. O método foi validado em termos de linearidade, limite de detecção e quantificação e recuperação. Os fatores de retenção para OT $\alpha$ e OTA foram de 2,1 e 6,8, respectivamente, resultando em um fator de separação de 3,2. Os limites de detecção quantificação para OTA foram de 0,025 e 0,05 ng. $\mathrm{g}^{-1}$ e para OT $\alpha$ de 0,013 e $0,025 \mathrm{ng} \cdot \mathrm{g}^{-1}$. A linearidade para OTA variou entre 0,05 - $5 \mathrm{ng} \cdot \mathrm{g}^{-1}$ ( $y=9.697,25 x-1481,97$ e $R=0,999)$ e para OT $\alpha$ variou entre $0,025-10$ ng.g $^{-1}$ $(\mathrm{y}=24435,41 \mathrm{x}+2762,62 \mathrm{R}=0,998)$. A recuperação dos analitos para farinha de trigo foi avaliada em três níveis $\left(0,1 ; 0,25\right.$ e $\left.0,5 \mu \mathrm{g} \cdot \mathrm{g}^{-1}\right)$, com faixa entre $96-112 \%$ para OT $\alpha$ e $75-90 \%$ para OTA. O método validado será empregado para avaliar a degradação enzimática de farinhas de trigo.

Palavras-Chave: CLAE, ocratoxina, farinha de trigo Agência de Fomento: 